Las Torres de Lucca. Revista internacional de filosofía política

ISSN-e: 2255-3827

\title{
Retrospectivas de la interseccionalidad a partir de la resistencia desde los márgenes ${ }^{1}$
}

\author{
Fabiana Parra ${ }^{2}$; Lucía Busquier ${ }^{3}$
}

Recibido: 05-02-2021 Aceptado: 30-08-2021 Publicado: 30-01-2022

Resumen. En este trabajo, proponemos mostrar que las múltiples experiencias de opresión-como efecto de las imbricaciones simultáneas entre instancias de diferenciación social y relaciones de poder- tienen como reverso experiencias de lucha, organización y resistencia colectiva como formas de participación política. Para el abordaje de las desigualdades entrecruzadas y diversas formas de violencia, proponemos un enfoque interseccional por su carácter multidimensional y complejo, así como por sus raíces de lucha. Para ello, en primera instancia, trazaremos genealogías políticas que permitan historizar la interseccionalidad y anudarla a sus luchas y demandas fundacionales. Analizaremos en esta dirección, las experiencias de la Colectiva del Río Combahee [Combahee River Collective] y de la Alianza de Mujeres del Tercer Mundo [Third World Women's Alliance], organizaciones feministas negras de la década del setenta en los Estados Unidos que buscaban enfrentar las desigualdades estructurales producidas por las articulaciones entre distintos sistemas de dominación y que direccionaron su participación política antiimperialista, anticapitalista, anticolonialista y antisexista. En un segundo momento, proponemos recuperar genealogías críticas de la interseccionalidad para repolitizarla y recomplejizarla, bajo el diagnóstico de neutralización y simplificación de la perspectiva. Finalmente, proponemos subvertir los binarismos dicotómicos y excluyentes bajo los cuales se han estructurado espacios de jerarquías y privilegios que reproducen violencias y desigualdades.

Palabras clave: genealogías; activismo; desigualdad; praxis; crítica.

\section{[en] Retrospectives of Intersectionality as of the Resistance from the Margins}

Abstract. In this paper, we propose that the multiple experiences of oppression -as an effect of the simultaneous entanglements between instances of social differentiation and power relations- have experiences of struggle, organization and collective resistance, $i$. e., different forms of political participation, as their reverse. To address intersecting inequalities and forms of violence, we propose an intersectional approach, due to its multidimensional and complex nature, as well as its roots in struggle. In the first instance, we will draw political genealogies that allow us to historicize intersectionality and tie it to its foundational struggles and demands. We will analyze the experiences of the Combahee River Collective and the Third World Women's Alliance, black feminist organizations of the 1970s in the United States that sought to confront the structural inequalities produced by the articulations between different systems of domination that oriented their anti-imperialist, anti-capitalist, anti-colonial and anti-sexist political participation. In a later instance, we propose to recover critical genealogies of intersectionality to re-politicize and recomplex it, under the diagnosis of the neutralization and simplification of the perspective. Finally, we propose to subvert dichotomous and exclusionary binarisms under which spaces of hierarchies and privileges have been structured and that reproduce violence and inequalities.

Keywords: Genealogies; Activism; Inequality; Praxis; Criticism.

Cómo citar: Parra, F. y Busquier, L. (2022). Retrospectivas de la interseccionalidad a partir de la resistencia desde los márgenes. Las Torres de Lucca. Revista internacional de filosofia politica, 11(1), 23-35. https://dx.doi.org/10.5209/1tdl.77044

El presente número especial sobre filosofía de la participación política convoca a pensar alternativas frente al despojo de agenciamientos políticos y epistémicos en el marco de las democracias contemporáneas, las cuales se encuentran atravesadas por "la creciente desigualdad política, la multiplicación y agudización de las crisis humanitarias y climatológicas," tal como afirma en la convocatoria del dossier. Particularmente, nos ha interpelado el interrogante: “¿Cuál es la mejor manera de lograr una participación política inclusiva?,” sobre

\footnotetext{
Este artículo fue realizado con el financiamiento de una beca otorgada por el Consejo Nacional de Investigaciones Científicas y Técnicas.

Fabiana Parra, Centro de Investigaciones en Filosofía, Instituto de Investigaciones en Humanidades y Ciencias Sociales (Consejo Nacional de Investigaciones Científicas y Técnicas), Facultad de Humanidades y Ciencias de la Educación, Universidad Nacional de La Plata, Argentina.

Correo electrónico fabianaparra00@gmail.com/

ORCID: https://orcid.org/0000-0001-5106-3675.

3 Lucía Busquier, Centro de Investigaciones sobre Cultura y Sociedad (Consejo Nacional de Investigaciones Científicas y Técnicas) y Centro de Investigaciones María Saleme de Burnichón, Facultad de Filosofía y Humanidades, Universidad Nacional de Córdoba, Argentina.

Correo electrónico: lu.busquier@gmail.com

ORCID: https://orcid.org/0000-0003-1174-2221
}

Las Torres de Lucca. 11 (1), 2022: 23-35 
el cual insistimos no tanto porque busquemos una respuesta cerrada, sino porque nos permite atender a las constantes tensiones dadas a nivel regional y global a partir de la existencia de agenciamientos alternativos que cuestionan la institucionalización de la falsa inclusión y la reproducción de múltiples desigualdades y exclusiones. Una muestra de estos agenciamientos está dada por la irrupción de importantes luchas contra los distintos efectos negativos del sistema capitalista y colonialista, que implican procesos de organización autónoma -al margen de los canales de representación política del Estado- manifestándose principalmente en formas de participación política directa como las asambleas, en las calles y en los territorios. Pensamos específicamente en el lema "la asamblea manda" de estudiantes secundarixs que tuvieron un rol decisivo en el proceso de "revuelta chilena," también conocido como "Chile despertó", que implosionó el 18 de octubre de 2019 con una enorme protesta callejera frente al aumento de tarifas del transporte en Santiago y que rápidamente se fue extendiendo a todo el país (Cf. Parra, 2019).

El punto de partida de un tratamiento atento a las complejidades de la multiplicidad de opresiones es el reconocimiento de que los espacios de privilegio que ocupan algunos sujetos en la estructura social tienen como reverso la exclusión de otros y son el efecto de procesos de jerarquización racial, sexual, de clase y de género, entre otras formas de opresión. En estas coordenadas ubicamos la posibilidad de reivindicar y (re)visibilizar la crítica y las luchas políticas efectuadas desde los márgenes para cuestionar y subvertir los centramientos hegemónicos excluyentes.

En este marco, consideramos pertinente recuperar la experiencia histórica de resistencias feministas soslayadas y opacadas por un feminismo hegemónico centrado en la experiencia de mujeres con privilegios de raza, clase, sexualidad y pertenencia geopolítica, como la de los feminismos negros. Si bien en la actualidad el término feminismo negro o feminismo afrodescendiente ha sido ampliamente recepcionado entre sus activistas, es importante señalar que en la década del setenta la denominación mujeres de color era empleada por diversos grupos de mujeres indígenas, negras, chicanas, migrantes, mestizas, mulatas, etc. bajo una resistencia colectiva contra las opresiones raciales. Según María Lugones (2008) dicha expresión permitía agrupar en una misma denominación a las mujeres "no blancas" a partir de una estrategia coalicional contra las opresiones múltiples. El feminismo negro estadounidense - que albergaba tradiciones marxistas, feministas y antirracistas-constituía una resistencia política con su crítica radical tanto al racismo de un feminismo blanco hegemónico y liberal conservador que no era sensible a las experiencias vividas desde el margen ${ }^{4}$ (hooks 1984; Davis, 1981) como al sexismo de los activistas afroamericanos que no advertían o querían atender al carácter generizado de la dominación racista o de la lucha de liberación negra (Viveros Vigoya, 2008).

A partir de allí, intentaremos mostrar que las contribuciones teóricas de las intelectuales feministas negras que a partir de la década del ochenta introdujeron en las agendas académicas reflexiones en torno al entrecruzamiento de opresiones tales como el género, la raza, la clase y la sexualidad se sustentan, principalmente, en las experiencias no solo personales sino también colectivas de diversas mujeres afrodescendientes que desde el momento de la esclavitud en los Estados Unidos desarrollaron diversas propuestas emancipadoras que buscaban combatir las opresiones de género y raza principalmente. Así, las raíces histórico-políticas de la perspectiva interseccional pueden encontrarse en, por ejemplo, diversas intelectuales afrodescendientes como Anna Julia Cooper, Ida B. Wells y Frances W. E. Harper quienes participaron en los clubes afrofemeninos de finales del siglo XIX o Elise Johnson McDougald quien en sus escritos de principios del siglo XX se refería a las intersecciones producidas entre el género, la raza y la sexualidad (González Ortuño, 2018: 245-246).

En ese mismo sentido, el discurso emitido por una mujer afrodescendiente hija de una esclava y un esclavo, llamada Sojourner Truth, quien en la Convención de los Derechos de la Mujer celebrada en Akron, Ohio, en 1852 reflexionaba sobre su condición de mujer, negra y esclava interpelando al público a partir de la pregunta “¿Acaso yo no soy una mujer?”, cuestionando así la mirada blancocentrada tradicional según la cual las afrodescendientes no eran entendidas como mujeres, sino como esclavas. Algo que, según palabras de María Lugones (2008) deviene de la bestialización de las poblaciones esclavas a partir de la conquista y, por consiguiente, catalogarlas como sujetos despojados de género. Es decir, que desde este marco de análisis, la imposición del género de manera dicotómica y jerárquica (varón/mujer) solo es aplicable entre humanos, por lo que quienes fueron convertidos en bestias carecen de género, lo que lleva a categorizar a las mujeres esclavas como hembras.

También podemos encontrar antecedentes de esta perspectiva en el movimiento artístico-político conocido como el Blues Clásico Femenino, movimiento musical, cultural y político integrado por mujeres afrodescendientes en las décadas del veinte y treinta en los Estados Unidos. Bessie Smith, Gertrude "Ma" Rainey, Sippie Wallace, Alberta Hunter e Ida Cox fueron algunas de las principales protagonistas de este movimiento que puede ser interpretado como un espacio de enunciación política donde a través de sus canciones problematizaron y cuestionaron el lugar que la sociedad estadounidense les imponía (Davis, 2012). Su participación política canalizada a través de sus canciones puede ser considerada como una herramienta

Retomamos la propuesta de bell hooks (1984) de comprender al margen como metáfora espacial, de un lugar subordinado e inferiorizado por una intersección de categorías de diferenciación social. 
de emancipación y resistencia hacia las múltiples opresiones de raza, género, clase que se articulan interseccionalmente (Busquier y Massó, 2018).

Tomando como punto de partida estas experiencias, en este artículo nos proponemos aportar al frondoso debate filosófico político en torno a la relación entre teoría y práctica -bajo la forma actualizada de relación entre academia y activismos-a partir del análisis de las experiencias múltiples y entrecruzadas tanto de opresión como de resistencias, de quienes se sitúan en los márgenes y ocupan posiciones subalternas por sus trayectorias sociales, culturales, políticas, sexuales y geopolíticas. En este marco formulamos la hipótesis que, dado que el enfoque interseccional se encuentra en estado práctico en los posicionamientos políticos antirracistas, antisexistas, anticolonialistas y antiimperialistas, recuperar esas genealogías de luchas y resistencias posibilita también recuperar el enfoque interseccional de manera recomplejizada y repolitizada.

Este énfasis en los orígenes de la interseccionalidad anudados a una práctica política confronta a aquellas lecturas como la de Linda Gordon (2020) que insisten en comprender a la interseccionalidad como "un señalador, que aísla el trabajo académico de quienes trabajan en incidencia y activismo" (p. 483). Lo cual implica subsidiariamente dos hipótesis diagnósticas: 1) reconocer que en las prácticas políticas de feministas negras de los sesenta y setenta existe una perspectiva interseccional atenta a los entrecruzamientos simultáneos en la multiplicidad de opresiones; 2) reconocer la creciente neutralización y simplificación de la interseccionalidad como efecto de su masificación acrítica e irrestricta en el ámbito académico, en la teoría feminista y en las políticas públicas. Atendemos en esta dirección a las críticas de feministas descoloniales como Ochy Curiel y Yuderkys Espinosa Miñoso a los procesos de oegenización del feminismo y a los procesos de creciente institucionalización de los postulados feministas "más revolucionarios" que -según esta perspectiva- al expandirse irrestrictamente no solo pierden valor heurístico y político, sino que también facilitan procesos de subversión y apropiación conceptual por parte de sectores adversos (Parra, 2021).

Para ello, en primera instancia, trazaremos genealogías políticas que permitan historizar el concepto y anudar la interseccionalidad a sus luchas y demandas fundacionales. Puntualmente analizaremos las experiencias de la Alianza de Mujeres del Tercer Mundo [Third World Women's Alliance] (TWWA) y de la Colectiva del Río Combahee [Combahee River Collective], organizaciones feministas negras de la década del setenta en los Estados Unidos. Su reconstrucción nos permitirá indagar sobre los orígenes de la perspectiva interseccional en el activismo. Lo que proponemos mostrar es la antecedencia práctica de un abordaje interseccional atento a la multiplicidad de opresiones como efecto de la imbricación de los sistemas de dominación (Curiel, 2010). Recurrimos a una estrategia filosófica proveniente del marxismo no ortodoxo, la lectura sintomal, con potencialidad de dar lugar a nuevas formulaciones y reconceptualizaciones "a partir de ausencias, lagunas y silencios teóricos" (Parra, 2021, p. 410).

Siguiendo esta dirección, buscamos dimensionar que, en las demandas de las feministas negras de ampliar el análisis de las opresiones teniendo en cuenta las interacciones dinámicas entre clase, raza, sexualidad y género (Colectiva del Río Combahee, 1988), se encuentra en estado práctico una perspectiva interseccional que busca dar cuenta de la superposición entrecruzada y simultánea de sistemas de dominación en las múltiples experiencias y agencias, mucho antes de que efectivamente el concepto haya sido explicitado por la abogada feminista negra Kimberlée Crenshaw en 1989 en el ámbito jurídico y adoptado en el espacio académico con un creciente reconocimiento en las investigaciones sociales.

De acuerdo con los objetivos planteados, en este escrito proponemos trazar genealogías feministas críticas que posibiliten construir memorias de luchas, de rebeldías y reconocer que, en los orígenes complejos de nuestros feminismos del sur, existen múltiples raíces. Una muy importante es la de los feminismos negros de los Estados Unidos que con su crítica al feminismo blanco eurocentrado inauguran un abordaje interseccional de las opresiones vividas, pero también de las resistencias frente a estas, lo que se tradujo en sus luchas antirracistas, anticapitalistas, anticolonialistas y antisexistas. Para Alejandra Ciriza (2015) es en clave crítica del eurocentrismo y del racismo -"en el terreno abrupto de nuestra compleja y fuertemente trágica historia"que las feministas del sur podemos rastrear los anclajes múltiples y contradictorios de nuestras prácticas políticas atendiendo a las "disímiles experiencias" (p. 83). En este marco, reconstruir memorias de rebeldías permite no solo reivindicar la práctica política de nuestras antecesoras sino también continuar sus luchas contra el capitalismo, el patriarcado, el racismo y la colonialidad en nuestra región.

Asimismo, retornar a estas resistencias permite - contra la neutralización y estabilización de la interseccionalidad- anudarla a la participación política de sectores subalternizados por razones de sexualidad, raza y clase, en búsqueda de inclusión social y ampliación de derechos. En vínculo con esto, en la segunda parte de nuestro trabajo abordaremos los términos y alcances de una crítica política de la interseccionalidad y propondremos alternativas frente a las neutralizaciones que acechan al término -en analogía con lo que ocurre con el de género- como efecto de su expansión acrítica.

Finalmente, argumentaremos que radicalizar la propuesta de crítica política a la interseccionalidad implica también radicalizar la crítica a una de las dicotomías propias del pensamiento occidental moderno: la que escinde teoría y práctica (Grosfoguel, 2013) para pasar a postular el carácter co-constitutivo, sobredeterminado y situado de toda intervención teórico-política. Examinar esta alternativa, sus implicancias y sus derivas actuales 
en la crítica a las meras formalizaciones y estabilizaciones enunciativas configura nuestras investigaciones posteriores.

\section{Raíces histórico-políticas de la interseccionalidad}

En este apartado nos proponemos recuperar la experiencia política de dos organizaciones pertenecientes al feminismo negro de los Estados Unidos: la TWWA y la Colectiva del Río Combahee. Es importante señalar que estos antecedentes no pretenden ser un recorrido acabado, sino que lo que se busca es presentar de manera ilustrativa dos experiencias que, desde el activismo y la participación política, sentaron las bases de lo que luego será conocida como la perspectiva interseccional a partir de la década del ochenta. Ambas organizaciones deben ser pensadas en un contexto en el que emergieron diversos grupos de mujeres negras, indígenas, chicanas, migrantes, lesbianas en los Estados Unidos, cuestionando los límites racistas que imponían las organizaciones pertenecientes al feminismo blanco y denunciando las prácticas machistas que debían enfrentar en el interior del colectivo afrodescendiente y la lucha antirracista.

Primeramente, resulta interesante rescatar la experiencia de la TWWA, organización que buscaba enfrentar las opresiones producidas por el género, la raza y el imperialismo, radicada en California y Nueva York entre los años 1970 y 1975. Esta organización impulsó gran cantidad de iniciativas que buscaban problematizar cómo estas opresiones atravesaban de manera particular a las mujeres del Tercer Mundo ${ }^{5}$ en un contexto caracterizado por las consecuencias de la Guerra de Vietnam (1955-1975), la legalización del aborto en 1973 a nivel nacional y las esterilizaciones forzosas aplicadas hacia dichas mujeres, entre otras. Esta organización se ubicó centralmente en la Ciudad de Nueva York a cargo de la activista Frances Beal y en California donde su principal referente fue Cheryl Perry. La lectura de su periódico publicado durante los cinco años de existencia denominado Triple Jeopardy permite indagar sobre el posicionamiento político que adquirió esta organización.

La TWWA enunciaba que sus estrategias principales se orientaban hacia la lucha contra el imperialismo, el sexismo y el racismo (Springer, 2006). En relación con el imperialismo, la TWWA se encargaba de denunciar las políticas imperialistas e intervencionistas impulsadas por Estados Unidos en países como Puerto Rico y en el conflicto Palestina-Israel. Además, cuestionaba el accionar del gobierno estadounidense en la Guerra de Vietnam donde el ejército estaba integrado principalmente por personas del Tercer Mundo que debían llevar a cabo un enfrentamiento armado contra otras personas del Tercer Mundo (Neale, 2003). Es por ello que para la TWWA éstas sufrían opresiones específicas y particulares que las diferenciaban, por ejemplo, de la clase trabajadora blanca o del feminismo blanco. Es decir, pertenecer al Tercer Mundo significaba no solo haber nacido en un país del Tercer Mundo o tener algún tipo de ascendencia, sino también compartir las mismas opresiones de clase, de género y de raza, lo que hacía aún más necesaria la unidad de las mujeres del Tercer Mundo para enfrentar a su enemigo común: el imperialismo. En una de sus publicaciones enunciaba:

The development of an anti-imperialist ideology led us to recognize the need for Third World solidarity. Although Asian, Black, Chicana, Native American and Puerto Rican sisters have certain differences, we began to see that we were affected by the same general oppressions [El desarrollo de la ideología antiimperialista nos llevó a reconocer la necesidad de la solidaridad del Tercer Mundo. Aunque las hermanas asiáticas, negras, chicanas, nativoamericanas y portorriqueñas tienen ciertas diferencias, empezamos a ver que todas éramos afectadas por las mismas opresiones generales]. (TWWA, 1971a, p. 8).

Sobre el sexismo y el racismo, la TWWA sostenía que las mujeres del Tercer Mundo debían enfrentar diversos tipos de violencias y discriminaciones particulares, lo que las diferenciaba de otros grupos como las mujeres blancas o los varones afrodescendientes. Puntualmente, analizaba el sistema productivo de los EE.UU. donde las mujeres del Tercer Mundo cumplían un rol fundamental como "mano de obra barata" y ocupándose principalmente del trabajo doméstico remunerado. A su vez, la legalización del aborto en 1973 a nivel nacional y la práctica de las esterilizaciones forzosas hacia las mujeres del Tercer Mundo impulsadas por el gobierno estadounidense eran otras de las preocupaciones que atravesaban a las intervenciones políticas de la TWWA.

Según su mirada, ambas estrategias empleadas por el Estado servían para ejercer un control de natalidad selectivo y una regulación sobre los cuerpos de las mujeres del Tercer Mundo. Entre las décadas del cincuenta y setenta hubo una intensificación de las políticas estatales apuntadas a regular el crecimiento poblacional que tomó diversas formas y estrategias dependiendo el contexto, siendo dos de ellas la legalización del aborto y la práctica de las esterilizaciones forzosas (Federici, 2011). De allí que la TWWA se refería a las esterilizaciones forzosas como un genocidio que les quitaba a las mujeres el control sobre sus cuerpos y denunciaba que el Estado utilizaba este método como una herramienta de control poblacional selectivo:

Elegimos emplear este término respetando la denominación utilizada por la organización para referirse a los diversos grupos de mujeres no-blancas. 
Birth control, abortion and sterilization is Genocide as long as Puerto Rican women and other Third World women don't have any control over their bodies. The capitalist system's reason for controlling women's bodies is to control the population of Puerto Ricans [Control de natalidad, abortos y esterilizaciones son un genocidio en todas las mujeres de Puerto Rico y otras mujeres del Tercer Mundo que no tienen ningún poder sobre sus cuerpos. La razón por la que el sistema capitalista controla los cuerpos de las mujeres es para regular la población de Puerto Rico]. (TWWA, 1971b, p. 5).

En suma, el activismo impulsado por la TWWA articulado a partir de su lucha contra la triple explotación -imperialismo, sexismo y racismo- permite rastrear, a partir de la práctica política y el accionar de diversas organizaciones de mujeres negras, las raíces histórico-políticas de lo que conocemos hoy como la perspectiva interseccional. Estas organizaciones articuladas en torno al feminismo negro nutrieron y gestaron una herramienta teórica y política que hasta el día de hoy resulta clave para problematizar y reflexionar sobre las distintas formas de opresión que atraviesan dichas mujeres (Busquier, 2019). Así, las producciones teóricas que se desarrollaron en el ámbito académico desde la década del ochenta con sus categorías y conceptos principales tienen su desarrollo, también, en el espacio del activismo por lo que dichas producciones académicas son más bien una consecuencia o un resultado de las propuestas impulsadas por los movimientos sociales que orientan sus luchas desde una perspectiva antirracista, antisexista y antiimperialista, como fue el caso de la TWWA.

La segunda organización que nos interesa rescatar es la icónica agrupación de feministas negras Colectiva del Río Combahee, que toma el nombre en homenaje a la ex esclavizada y abolicionista Harriet Tubman. Nacida en Boston, su conformación en 1974 agrupó a gran cantidad de mujeres afrodescendientes que buscaban enfrentar las opresiones producidas por el género, la raza, la clase y la sexualidad. La publicación de Un Manifiesto Feminista Negro [Combahee River Collective Statement] en abril de 1977 resultó de suma importancia a la hora de esclarecer y sintetizar los debates que se venían desarrollando en el feminismo negro de los Estados Unidos y fue un antecedente fundamental para las producciones teóricas que se realizaron en la década siguiente. Las feministas negras de la Colectiva del Río Combahee buscaron "desarrollar un análisis y una práctica basados en el principio de que los sistemas de opresión racial, sexual, heterosexual y de clase estaban interrelacionados de tal forma que era difícil distinguirlos en la experiencia concreta de las mujeres racializadas" y buscaron conceptualizar "la articulación de las relaciones de clase, de género y de raza" (Viveros Vigoya, 2008, p. 173).

Frente a un feminismo blanco liberal hegemónico que no era sensible ni solidario con la violencia racial que sufrían las mujeres y lesbianas negras y frente a la ceguera de género de los movimientos en los que se referenciaban como el nacionalismo negro y organizaciones de izquierda, las feministas afroamericanas se organizaron en un espacio político de alianzas y luchas comunes -la Colectiva del Río Combahee- para enfrentar los efectos de la dominación de género, de clase, del racismo y del heterosexismo y para enfrentar desde una práctica feminista tanto el antirracismo (ninguneado por el feminismo blanco) como el antisexismo (invisibilizado en el movimiento negro dentro del que ellas se referenciaban). Así lo afirmaban con las siguientes palabras:

Creemos que la política sexual bajo el patriarcado es tan penetrante en la vida de las mujeres Negras como lo son las políticas de clase y raza. A menudo nos parece difícil separar opresión racial, opresión de clase y opresión sexual porque en nuestras vidas la mayor parte del tiempo las experimentamos simultáneamente. Sabemos que existe tal cosa como la opresión racial-sexual que no es ni solamente racial ni sólo sexual; por ejemplo, la historia de la violación de hombres blancos a mujeres Negras como arma de represión política. (Colectiva del Río Combahee, 1988, p. 175).

El Manifiesto publicado por primera vez en 1977 pone de relieve cómo el feminismo negro privilegia la especificidad de las experiencias de opresión de las mujeres negras - "el punto de vista de las mujeres negras" (Hill Collins, 2000) - y al entendimiento político de estas experiencias, aparentemente "personales" en las que la opresión sexual sufrida por las mujeres negras era constante y cotidiana. Puesto que al imbricarse con la racial -que existía de manera omnipresente en la vida de las mujeres negras tal como ellas afirman- redobla la vulnerabilidad de éstas: en tanto mujeres y lesbianas y en tanto negras.

La omnipresencia del racismo es identificada por las feministas negras como un obstáculo para la construcción de una política feminista negra, que solo podía ser posibilitada por las herramientas tokenistas en educación y empleo que les permitía luchar de manera más efectiva contra la opresión sexual y racial. Según Blas Radi (2020) el tokenismo suele traducirse como florerismo y fue impulsado por el movimiento afrodescendiente en la década del sesenta en Estados Unidos para cuestionar la baja representación de las personas racializadas en las escuelas y en las fábricas del sur de EEUU. En las décadas siguientes fue recuperado por intelectuales afrodescendientes y feministas para referirse a una inclusión simbólica a través de pequeñas y superficiales concesiones a grupos minoritarios buscando evadir señalamientos y acusaciones por discriminación. Con ello, se intenta generar una ficción de igualdad o diversidad aparentando una imagen progresista e inclusiva. 
Sin embargo, como las mismas feministas negras identifican, nadie antes se había interesado en examinar la "textura múltiple de las vidas de las mujeres negras" (Colectiva del Río Combahee, 1988, p. 175). Al exigir la inclusión de las experiencias de género, raza y clase de las mujeres no blancas "en niveles teóricos, prácticos y políticos, de distintas, simultáneas e intersectadas formas de opresión" (Viveros Vigoya, 2016, p. 9) el feminismo negro no solo produjo una ruptura epistemológica con el feminismo blanco hegemónico. Además, constituye un antecedente de repolitización de las perspectivas teóricas que a menudo se autodenominan emancipadoras pero que con sus centramientos - anclados en una lógica dicotómica y binaria- producen nuevos borramientos y exclusiones.

Frente a las políticas de carácter centrado-excluyente de los enfoques identitarios, experiencias como la de la Colectiva del Río Combahee proponen la articulación a partir de las diferencias para la construcción de alianzas políticas, y la construcción de una política en común (Gandarias Goikoetxea, 2017; Cole, 2008). Bajo esta lectura es posible comprender la praxis de las feministas negras como un ejemplo de la interseccionalidad política, es decir como una herramienta política para la construcción de alianzas. ${ }^{6}$ También autoras del pensamiento feminista negro como Audre Lorde proponen "aprender a tomar nuestras diferencias y hacerlas fuerzas" (Lorde, 1988, p. 91), frente a una tradición política que escatima las diferencias tras comprenderlas como un motivo de separación.

\section{Epistemologías críticas y genealogías políticas desde los márgenes}

El feminismo negro estadounidense de las décadas de los sesenta y setenta cuestionó las jerarquías dentro de los movimientos emancipadores como el feminista con regímenes diferenciales de visibilización de ideas y problemas centrados en las experiencias de algunas mujeres (con privilegios de raza, clase y sexualidad) con pretensiones de universalidad, lo que tenía como reverso la invisibilización e inferiorización de quienes se posicionan en los márgenes.

La publicación de El Segundo Sexo en Francia en 1949 por la filósofa feminista Simone de Beauvoir marcó un punto de inflexión en los debates que se desarrollaban en el interior de los feminismos, ya sea en la academia como en el activismo. La separación entre el sexo biológicamente predeterminado y el sexo culturalmente construido, es decir el género, ponía en evidencia que no existiría ningún destino biológico, psíquico o económico que defina a las mujeres como tales, sino que es el conjunto de la sociedad la que elabora al sujeto mujer (de Beauvoir, 2019). Sin embargo, en las décadas del sesenta y setenta, esta nueva forma de distinción entre sexo/género decantará en la construcción de un modelo particular de sujeto mujer con ciertas características que tendía a homogeneizarla en una imagen estándar de lo que es (o debería ser) (Stolcke, 2004).

Esta perspectiva presentará ciertas limitaciones a la hora de entender el binomio sexo/género ya que si bien esta división permitió comprender que no existía nada que predeterminara al género de las personas, no sucedió lo mismo con el sexo. Esto generó que se idealizaran ciertas expresiones de género como verdaderas, es decir, se constituyó un ideal de mujer blanca, cis, heterosexual y de clase media, estableciendo jerarquías y excluyendo a otros grupos como las lesbianas, gays, transexuales, migrantes, afrodescendientes e indígenas (Mattio, 2012).

En este contexto se hicieron explícitas algunas críticas dentro de los estudios de género y las organizaciones feministas por parte de otros grupos sociales que manifestaban la importancia de reconocer las diversidades y otros colectivos dentro del concepto homogéneo de mujer y planteaban la necesidad de entenderlo como un término amplio, plural y heterogéneo (Krolokke y Scott Sorensen, 2006). Por su parte, las mujeres afrodescendientes pusieron el acento en la diversidad del género desde el punto de vista de la raza, la clase y la sexualidad aportando argumentos desde las propias vivencias, contra los centramientos y las pretensiones universalistas de ciertas prácticas y teorías. Es por ello que en la década del sesenta comenzaron a plantear que el género, tal como había sido definido por varias disciplinas y organizaciones feministas, resultaba insuficiente para explicar las diversas opresiones que las afrodescendientes enfrentaban más allá de su condición de mujeres. Es decir, para ellas, las desigualdades de género eran racializadas y, al mismo tiempo, las desigualdades socioraciales estaban atravesadas por el género (Stolcke, 2004).

bell hooks, escritora y activista negra, es una de las exponentes del feminismo negro de los Estados Unidos. A partir de sus experiencias individuales atravesadas por las múltiples opresiones de género, raza, clase y sexualidad, en sus escritos ofrece un análisis político y teórico que resignifica los márgenes del feminismo y visibiliza el lugar secundario que debían ocupar las mujeres afrodescendientes en el interior del colectivo de mujeres que se concentraban exclusivamente en el género como único determinante de sus destinos. Para la autora, la literatura producida por las feministas blancas estaba atravesada por un importante racismo que negaba la participación política de las mujeres negras en el movimiento feminista generando la falsa idea de que el género, la raza y la clase eran asuntos separados. En contraposición a eso, hooks (2004) entendía que

Agradecemos muy especialmente a las evaluaciones del artículo por iluminar este punto. 
las estructuras de clase en la sociedad estadounidense estaban conformadas a partir de criterios raciales, por lo que solo a través del análisis sobre el racismo y de su lugar en la sociedad capitalista sería posible comprender de manera acabada las relaciones de clase.

Así, el feminismo negro redefine el concepto de opresión al incorporar la noción de matriz de dominación (Hill Collins, 1998) y al adoptar la "teoría del punto de vista" como bases del pensamiento feminista negro, enfatizando la perspectiva de las propias mujeres negras sobre sus experiencias vividas. En efecto, distintas autoras afrodescendientes han partido del análisis de prácticas políticas como base para la construcción de saberes en la academia retomando la propuesta del "punto de vista" procedente de la epistemología feminista crítica -que nuclea a autoras blancas norcéntricas como Donna Haraway, Sandra Harding, Nancy Harstockpara poner en cuestión las formas estandarizadas de la producción de saberes en el marco de una lógica eurocéntrica y moderna, permitiendo vislumbrar cómo raza, género y clase se entrelazan dentro de la matriz de poder en el orden social.

Sin embargo, si bien en sus orígenes la propuesta del "punto de vista" por parte del feminismo blanco sirvió para cuestionar el androcentrismo y la objetividad en las ciencias, terminó por reforzar un sujeto mujer universal y homogéneo que, según las autoras afrodescendientes, solo expresaba el punto de vista de las mujeres blancas, de clase media y heterosexuales (Espinosa Miñoso, 2019). Por el contrario, estas autoras feministas afrodescendientes proponen recuperar las diversas experiencias, en este caso de las mujeres negras, para llevar adelante nuevas epistemologías críticas producidas a partir de saberes situados. Esto posibilitó cuestionar aquellas ideas que tendían a universalizar y homogeneizar al sujeto mujer, perdiendo de vista las pluralidades y singularidades propias del colectivo de mujeres en general y de las mujeres afrodescendientes en particular.

A partir de la década del ochenta comenzaron a salir a la luz textos producidos por intelectuales negras en el espacio académico. Entre las principales exponentes de lo que se conoce como pensamiento feminista negro se destacan bell hooks, Audre Lorde, Angela Davis, Patricia Hill Collins y Kimberlée Crenshaw, entre otras. Según Patricia Hill Collins (2012), socióloga y activista afrodescendiente, ese pensamiento tiene como principal objetivo enfrentar las múltiples opresiones de raza, género y clase que atraviesan las mujeres negras, ya sea de manera simbólica o física, buscando establecer lazos entre dichas mujeres quienes a partir de sus experiencias individuales puedan generar una conciencia colectiva

Dentro de esta propuesta epistemológica, la idea de triple opresión compuesta por el género, la raza y la clase a la que se referían las feministas negras de la época adquirió diversas denominaciones y definiciones tales como simultaneidad de opresiones impulsada por la Colectiva del Río Combahee anteriormente mencionada. Otra de ellas fue la perspectiva interseccional o interseccionalidad propuesta por la abogada y docente universitaria Kimberlée Crenshaw $(1989,1991,2012)$. Crenshaw sostiene que las realidades de las mujeres negras no pueden ser explicadas a partir del género o de la raza de manera separada. Por el contrario, adquirir una perspectiva interseccional serviría para observar "las distintas formas en las que la raza y el género interactúan y cómo generan las múltiples dimensiones que conforman las experiencias de las mujeres negras" (2012, p. 89).

Crenshaw formuló este término para abordar en el terreno jurídico la invisibilización por parte del poder judicial de la existencia de múltiples formas de opresión que las trabajadoras afrodescendientes debían enfrentar en la compañía General Motors de los Estados Unidos. A partir de este caso puntual intentó generar herramientas jurídicas concretas para visibilizar y combatir aquellas violencias y discriminaciones producidas por el género y la raza (Viveros Vigoya, 2016). Para Crenshaw, el tratamiento por separado de las discriminaciones de raza y género, como "categorías mutuamente excluyentes de la experiencia y el análisis," tenía consecuencias problemáticas para la jurisprudencia, para la teoría feminista y para las políticas antirracistas. Por ese motivo proponía comprender que "la intersección del racismo y del sexismo en las vidas de las mujeres Negras afecta sus vidas de maneras que no se pueden entender del todo mirando por separado las dimensiones de raza o género" (Crenshaw, 2012, p. 89).

En otras palabras, la interseccionalidad refiere al modo en que las estructuras que conjugan las desigualdades se relacionan entre sí, donde las categorías como el género, la raza y la clase no son consideradas como determinantes, sino que, por el contrario, son el producto de construcciones sociales. Al mismo tiempo, estas categorías no corresponden a una sumatoria de opresiones en la vida de un sujeto, sino que estas desigualdades actúan de manera múltiple, variada y recíproca (Platero, 2012).

Estas propuestas teóricas que surgen a partir de la década del ochenta, enmarcadas dentro del pensamiento feminista negro y de una nueva epistemología crítica, se asientan sobre las bases de los activismos y la participación política de las mujeres afrodescendientes que se desarrollaron en las décadas anteriores. Tal es el caso de la TWWA y la Colectiva del Río Combahee, como ejemplificamos en el apartado anterior. Sus estrategias de lucha y resistencia se orientaron por la lucha contra las violencias y discriminaciones producidas por las interacciones y entrecruzamientos entre distintos sistemas de poder. Sumado a ello, las críticas hacia el racismo instituido en las organizaciones feministas blancas y al machismo presente en los colectivos afrodescendientes sentaron las estructuras -teóricas y políticas-donde se construyeron las propuestas teórico- 
epistémicas que buscan explicar las imbricaciones producidas entre los diversos sistemas de poder como lo son la perspectiva interseccional y la matriz de dominación.

Recuperar estas experiencias políticas permite poner en cuestión la neutralización de la interseccionalidad, producto de lo que conjeturamos su masificación acrítica, y problematizar el espacio fronterizo que divide a la teoría de la práctica política presente en el pensamiento occidental moderno.

\section{Crítica política de la interseccionalidad}

La interseccionalidad es formulada explícitamente en el campo jurídico y luego es adoptada por las Ciencias Sociales y principalmente por los estudios de género y feministas. Sin embargo, desde hace unos años se advierte una serie de fenómenos correlativos a la masificación acrítica del concepto de interseccionalidad. Por un lado, se ha advertido que este se ha expandido sin precisiones ni rugosidades teóricas (González Ortuño, 2016); así como de manera desigual a nivel disciplinar y geopolítico (La Barbera, 2016); por lo cual se torna necesario realizar exploraciones teóricas ulteriores y mayor difusión fuera del ámbito académico anglosajón. En cuanto al primer aspecto crítico, se ha advertido que el concepto de interseccionalidad se estabiliza como una herramienta analítica -la "santa trinidad"- en espacios académicos, principalmente feministas y de género y se expande también a otros estudios sociales y políticas públicas de manera exponencial; consecuentemente se simplifica y se neutraliza. Críticamente señala González Ortuño (2016):

La interseccionalidad se transformó en una palabra de moda en congresos y simposios, se crearon departamentos de investigación y ONGs para desarrollar estudios interseccionales en el ámbito de la economía, el derecho, la sociología, la cultura y las políticas públicas. A la trilogía de género, raza y clase se agregaron otros vectores de opresión como la sexualidad, la nacionalidad, la edad o la diversidad funcional. (p. 532).

Bajo nuestro análisis, la interseccionalidad se masifica y neutraliza de manera análoga a lo que ocurre con el concepto de género en los ámbitos académicos. Retomamos en esta dirección la crítica política que se ha realizado al proceso de oenegización del género (Mendoza, 2014) puesto que, si bien le permitió al feminismo (hegemónico) articular con el Estado a través de organizaciones sociales e instituciones públicas, ha tenido un efecto negativo: la pérdida gradual de su politicidad y crítica inherente "que lo ha llevado a abandonar buena parte de sus postulados políticos más éticos y revolucionarios” (Curiel, 2010, p. 73).

Siguiendo esta lectura crítica de los procesos de institucionalización, estabilización y neutralización de perspectivas subversivas y desestabilizadoras del status quo como la de género, se puede decir que la masificación acrítica del concepto no solo ha tenido efectos de simplificación y neutralización -que en última instancia, reinstauran una perspectiva binaria excluyente que escinde teoría y práctica- sino que además facilitan procesos de apropiación y subversión conceptual por parte de sectores reaccionarios a la ampliación de derechos de sectores minoritarios, que los utilizan con fines adversos. De este modo, si bien la incorporación del concepto género en la teoría feminista se proponía superar el carácter excluyente del concepto monolítico y homogéneo de mujer, como bien se ha criticado desde hace más de dos décadas desde los márgenes del feminismo hegemónico, ha sufrido procesos de mera formalización vinculados a su estabilización institucional y su reduccionismo. Frente a esto, se torna vital estudiarlo en perspectivas críticas que permitan comprenderlo como parte de un entramado complejo en el que se articula con el sexo, la raza, la clase, la edad, la pertenencia geopolítica, entre otras variables.

Contra el reduccionismo y la neutralización de conceptos críticos como el de género y el de interseccionalidad, proponemos recuperar tradiciones políticas y genealogías críticas que posibiliten visibilizar el anudamiento intrínseco que existe en determinadas experiencias de resistencia entre teoría y práctica -subvirtiendo una lógica tradicional que insiste en escindirse- al mostrar que los orígenes del concepto están anudados a la participación política realizada desde los márgenes: mujeres y lesbianas negras, feministas de los Estados Unidos que debían luchar contra el racismo, el clasismo y el sexismo de los espacios políticos en los que se referenciaban. Con lo cual el trazado de genealogías críticas permite, además de recomplejizar la perspectiva interseccional, mostrar su núcleo práctico-político.

En este sentido es que se torna urgente desde nuestra perspectiva reconocer el legado de las feministas negras para construir una teoría enraizada en las propias experiencias de opresión y de lucha de las mujeres lesbianas, indígenas, negras, pobres, migrantes, mestizas y racializadas. Reconocer la inscripción compleja de prácticas interseccionales en espacios fronterizos, entre academia y activismo, entre teoría y práctica y, en última instancia, entre cuerpo y política (Ciriza, 2015; Ochoa, 2012). En estrecha relación con lo anterior, la propuesta busca también interpelar a la propia práctica académica que corre riesgos de neutralizarse al ajustarse a los criterios de ubicuidad de la ciencia moderna y promover la integración de las propias experiencias de exclusión y de privilegios -siguiendo la propuesta de los feminismos negros de poder también "narrar nuestras experiencias en primera persona" (hooks, 2004)-. 
La posibilidad de enunciación y agencia epistémica (Medina Martín, 2014) tiene estrecha relación con la crítica que desde epistemologías otras a las tradicionales y canónicas se realiza a los espacios de privilegio que se constituyen en la academia en detrimento de los espacios de invisibilización y borramiento de producción de conocimientos desde los márgenes. ${ }^{7}$ Una muestra de ello, en el terreno de los estudios de género y feministas, consiste en que las teóricas feministas blancoburguesas recepcionan e incluso incorporan debates generados por los márgenes del feminismo, pero no trastocan sus construcciones teóricas basadas en la primacía del género para explicar la subordinación de "todas las mujeres". ${ }^{8}$ De allí la importancia de las perspectivas y prácticas interseccionales y situadas desde las condiciones específicas de subordinación de las distintas posiciones del sujeto en particular de las más excluidas. En ese sentido, se reconoce que las mujeres no son un grupo homogéneo o estable en el tiempo y en el espacio, sino que se trata de una categoría política. De esta manera se articulan localizaciones específicas, materialidades concretas, así como memorias e historias diversas de subordinación, pero también múltiples experiencias de resistencias y luchas. Tales experiencias constituyen el material a partir del cual los feminismos descentrados aportan sus visiones que dan cuenta de "la multiplicidad de opresiones que viven las mujeres, así como matrices de opresión en las que se entrecruzan la opresión patriarcal, la opresión clasista, racista, heterosexista, entre otras" (Parra, 2018, p. 93). Este posicionamiento epistemológico y político descentrado configura los trazos para introducir ideas y debates sintomáticamente ausentes, y desplazados en el marco del pensamiento hegemónico con sesgos de raza, sexo, género, sexualidad y clase.

En esta dirección, Audre Lorde denuncia la ceguera racial de las feministas liberales que niegan las diferencias de las mujeres negras y del tercer mundo. Y recuperando el pensamiento de Adrianne Rich interpela al racismo de las feministas blancas que durante los últimos años se han educado enormemente, pero no se han educado sobre las mujeres negras y las diferencias entre blancas y negras, siendo que es la clave, según Lorde, de la sobrevivencia del movimiento feminista.

Por ello, Lorde cuestiona la falsa inclusión -lo que Gloria Anzaldúa (2016) llama "inclusión a medias"de posiciones políticas que niegan las diferencias al investir bajo discursos de igualdad y fraternidad lo que concretamente son prácticas excluyentes, puesto que no trastocan en absoluto el privilegio de quienes se encuentran en el lugar dominante. Frente a esto, Lorde hace una invitación a romper con la ilusión tramposa de una fraternidad sin diferencias, que elude el conflicto y la desarticulación de las tramas que producen las desigualdades. Para la activista afronorteamericana, de lo que se trata es de establecer alianzas y habitar orgullosas la casa de la diferencia. Lo contrario implica ser condescendiente con el amo, y mantener intacta su casa, las bases que la sostienen y que permanecen intocables.

A propósito de no buscar desarmar la casa del amo con las herramientas del amo, Lorde critica la propuesta de educación de los sectores privilegiados a partir del conocimiento de los sectores oprimidos, puesto que no solo refuerza la explotación de estos últimos al redoblar su trabajo, sino que además inviste la desigualdad estructural de una falsa igualdad. Una inclusión real implica prácticas integrales y radicales, no puede implicar jamás una tarea que recaiga exclusivamente sobre quienes se encuentran en una relación en el lugar de subalternidad, inferioridad u objetividad. Desde una posición epistémica de tipo empirista, el conocimiento es concebido como una relación preestablecida de sujeto a objeto, donde el primero extrae la esencia al segundo.

El extractivismo académico y el borramiento de las producciones epistémicas desde el margen es abordado por la filósofa argentina Moira Pérez como causa y efecto de la violencia epistémica comprendida como un tipo de violencia específica ejercida en relación con la producción, circulación y reconocimiento del conocimiento que implica "la negación de la agencia epistémica de ciertos sujetos, la explotación reconocida de sus recursos epistémicos, su objetificación entre muchas otras cosas" (Pérez, 2019, p. 82). Consideramos que la crítica a los sesgos racistas, sexistas, cissexistas, euronorcentristas en las prácticas y teorías que forman parte de los procesos de conocimiento es central para subvertir las lógicas de dominación y desigualdad epistémica.

En esta línea, cabe señalar que desde perspectivas críticas del colonialismo y referenciadas en las prácticas políticas de los feminismos negros se ha cuestionado el régimen privilegiado de visibilidad del que gozan las producciones de conocimiento del Norte en relación con el Sur Global y se ha cuestionado el circuito unidireccional de circulación de ideas y teorías desde el centro a las periferias. Asimismo, dichas perspectivas críticas pretenden construir y fortalecer prácticas y saberes que nos definan de manera más genuina ante imposiciones de contextos, luchas, soluciones problemáticas, externas y ajenas (Sciortino, 2014).

Finalmente y en relación con lo anterior, proponemos romper ${ }^{9}$ con toda forma de centramiento que reproduce desigualdades y que se encuentra anclado a la lógica dicotómica y binaria, propia de la epistemología

Existen también, márgenes radicales en el que voces entrecruzadas son sistemáticamente excluidas y silenciadas como ocurre con quienes se encuentran en contextos de encierro punitivo. Para ampliar sobre esta cuestión, invitamos a recorrer investigaciones actuales enfocadas en las múltiples violencias que sufren personas trans en contexto de encierro punitivo que - desde una perspectiva interseccional y antipunitivista- argumentan por qué son obsoletas las prisiones - parafraseando a Angela Davis (2003)- e invitan a recuperar la agencia epistémica y política de estos sectores al "explorar algunas estrategias de agencia y resistencia que ellas generan para sobrevivir y resistir al encierro" (Pérez y Bissutti, 2021, p. 229).

En esta dirección, se han propuesto términos como el de transfeminismo para habilitar "otras formas de devenir-mujer" (Perlongher, 1997).

Utilizamos el término "romper" aludiendo a la tradición filosófico-materialista que reivindica la "ruptura epistemológica" como condición de posi- 
tradicional moderna. Conjeturamos también, para desarrollar en futuras investigaciones, que en el ámbito académico la eliminación de las desigualdades y violencias específicas se encuentra obstaculizada por las meras formalizaciones y enunciaciones -ajustadas a los patrones de ubicuidad y neutralidad científica- que radicalizan aún más las prácticas excluyentes, pero investidas de lemas de inclusión social, epistémica y política.

Este mecanismo doble de exclusión/inclusión en la academia puede ser ilustrado con la inclusión de problemáticas de las minorías por parte del mainstream académico, que sólo opera como un gesto superficial de apertura y sensibilización, pero no implica transformaciones integrales ni sustanciales de las relaciones de poder que mantienen espacios de jerarquías y privilegio epistémico que reproducen la visibilidad de determinadas/ os académicas/os sobre otras/os/es. Este privilegio epistémico se encuentra, asimismo, entramado con otros privilegios estructurales vinculados a la pertenencia geopolítica, por ejemplo, en el caso de las producciones teóricas sobre racismo y colonialidad, que crecen de manera escalonada en la última década por parte de académicxs euronorcéntricxs.

La apropiación de demandas de sectores minoritarios por parte de sectores de poder y la conversión en políticas públicas de consignas y lemas políticas se encuentran en un terreno espinoso cuando no trastocan los privilegios y las jerarquías. En este sentido, por ejemplo, podría pensarse, siguiendo a Sarah Ahmed (2010) en la estrategia de instituciones universitarias frente a la violencia sexual sufrida en el ámbito educativo que consiste en dilatar el proceso de resolución efectiva del problema con el redireccionamiento a distintas secretarias creadas justamente "para que se crea que se está haciendo algo" cuando en realidad se trata de mera burocracia institucional. Algo similar ocurre con la falsa inclusión de sectores minoritarios en la vida política de un espacio que en realidad no pretende su participación integral y plena, sino meramente difundir la idea de que ese espacio de jerarquías y privilegios es tolerante con las diferencias, pero intolerante con las rupturas sostenidas contra los sistemas de poder a través de todo un eslabonamiento de prácticas.

La creación de baños mixtos en universidades latinoamericanas desde hace una década puede ser leída como ilustrativa de los procesos de dilación institucional. Proponemos para ello pensar en la siguiente situación: si se trata de un baño aislado en términos espaciales y también en términos numéricos y si, además, no existe de manera integral una educación sexual no binaria para que pueda ser comprendida la importancia de su existencia, difícilmente implique una herramienta política, capaz de romper con los binarismos excluyentes. A su vez, más fácilmente pasará a formar parte de muchas de las estrategias políticas progresistas que buscan eludir el conflicto mediante gestos floreristas, característicos de los espacios institucionales académicos.

\section{Conclusiones}

A modo de cierre, resulta interesante destacar que el pensamiento feminista negro, en primer lugar, proviene de las diversas expresiones políticas y artísticas desarrolladas por mujeres negras, quienes desde el periodo esclavista problematizaban los cruces existentes entre las diversas opresiones, experiencias e identidades que las atravesaban como mujeres, negras, esclavas, pobres, lesbianas y migrantes. Esto permitió construir sus propias herramientas teóricas y analíticas enmarcadas en diversas propuestas epistemológicas. Las producciones de las intelectuales afrodescendientes que componen el pensamiento feminista negro, entonces, se asientan en las experiencias y en el punto de vista propio de las mujeres negras, lo cual permite construir un conocimiento situado y especializado.

En segundo lugar, la construcción de esta epistemología permitió discutir la idea de mujer como un sujeto homogéneo y universal enriqueciendo dicha categoría a partir de la raza y la clase, principalmente, para entender las realidades de las mujeres negras. Es decir, las categorías que emergieron de estos feminismos desde los márgenes como el racismo, el capitalismo, la nacionalidad, la sexualidad, entre otras, se entrecruzaron con la categoría sexo-género propuesta por el pensamiento feminista blanco complejizándola, enriqueciéndola y potenciándola. Este cruce de categorías, además, debe ser pensado desde un conocimiento situado y localizado para evitar caer en generalizaciones y universalismos. Reconocer y visibilizar las voces de las mujeres racializadas dentro del pensamiento feminista permite legitimar las agencias políticas de éstas, así como también su capacidad de enunciación teórica y epistémica.

Tercero, la participación política de las mujeres afrodescendientes en el espacio académico resulta clave para garantizar la incorporación de estudios y la producción de saberes que busquen problematizar las intersecciones producidas entre las diversas relaciones de poder como el género, la raza y la clase. Al mismo tiempo, esa construcción de conocimientos deberá estar anclada en las prácticas políticas concretas impulsadas por los movimientos sociales y, en este caso, por el feminismo negro. Dichos saberes podrán ser pensados como una herramienta emancipadora con las que se busque combatir los efectos producidos por la Colonialidad del Saber (Lander, 2016). De esta manera, lo que resultará en última instancia es un diálogo y un entrecruzamiento constante entre las prácticas políticas impulsadas por los diversos activismos y los saberes producidos en el

bilidad de procesos emancipadores (Parra, 2018). 
espacio académico que promuevan una descolonización de los conocimientos. En la región latinoamericana y caribeña, autoras como Lélia Gonzalez $(1983,1988)$ y Sueli Carneiro (2005), activistas e intelectuales afrobrasileñas, son claros ejemplos de cómo es posible encarnar una práctica política antisexista y antirracista $\mathrm{y}$, al mismo tiempo, formar parte del espacio académico buscando desarrollar propuestas epistémicas que también apunten a combatir dichas opresiones.

Como parte de nuestro propósito teórico-político de romper con centrismos y binarismos excluyentes y como parte de nuestra contribución a los objetivos del presente dossier sobre filosofía de la participación política, buscamos potenciar redes que permitan visibilizar y reconocer los conocimientos y prácticas políticas realizadas desde los márgenes, así como a abogar desde nuestros lugares y posiciones por prácticas que permitan redistribuir recursos materiales y reestructurar las posibilidades de circulación de la palabra. Concretamente y desde una crítica política a las meras formalizacione ${ }^{10}$ de perspectivas críticas -como la de género, y la interseccional-, en el ámbito académico ajustarse a los parámetros de ubicuidad de la ciencia moderna solo impide dilucidar los problemas, eliminar las violencias y erradicar las desigualdades. Frente a esto, extremar la crítica y ejercerla de manera constante, sin dogmatismos ni limitaciones por adhesiones políticas, es una posibilidad que se puede ejercer desde posicionamientos descentrados y desde los márgenes, que buscan establecer alianzas, tramar redes y resistir colectivamente a los sistemáticos intentos de aniquilamiento y silenciamiento de las voces entrecruzadas. Esta resistencia desde los márgenes implica atender al llamado de Lorde (1988) de promover el autocuidado y la autoconservación porque nadie más lo hará por nosotrxs en un contexto de guerra política.

El recorrido de nuestro trabajo partió de la pregunta "¿cuál es la mejor manera de lograr una participación inclusiva?," retomando el interrogante planteado en la convocatoria del presente dossier. No pretendimos dar una respuesta acabada, pero sí argumentamos nuestra propuesta de recuperar las praxis interseccionales de quienes sufrieron múltiples opresiones y supieron hacer de esa experiencia un lugar de resistencia y de lucha a través de alianzas con pares en situación de opresión, principalmente contra la dominación enmascarada y edulcorada. Con estas líneas, esperamos contribuir a la recuperación de estrategias políticas para resistir y batallar frente los espacios jerárquicos de poder, promoviendo subversiones programáticas en nuestras democracias contemporáneas, cada vez más ornamentales y maquilladas. Este desafío implica seguir un camino sinuoso, pero al mismo tiempo necesario y urgente, ya que a nuestro entender supone un acto de justicia epistémico-política ineludible.

\section{Referencias bibliográficas}

Ahmed, Sarah (2010). The promise of happiness [La promesa de la felicidad]. Duke University.

Anzaldúa, Gloria (2016). La frontera/borderlands: la nueva mestiza. Capitán Swing.

Busquier, Lucía y Massó, Mariana (2018). El blues clásico femenino y la emancipación de las mujeres de color en Estados Unidos (1920'-1930'). Revista Aesthethika. Revista internacional sobre subjetividad, política y arte, 14(1), 31-41. https://www.aesthethika.org/El-Blues-Clasico-Femenino

Busquier, Lucía (2019). Los inicios de la interseccionalidad: orígenes, debates y militancia política de la Third world women's alliance en el marco del feminismo negro norteamericano (1970-1975). Revista sintesis, (8), 49-64.

Carneiro, Sueli (2005). Ennegrecer el feminismo. Nouvelles questions féministes. Revue internationale francphone, 24(2), 21-26. https://julesfalquet.files.wordpress.com/2010/05/feminismos-disidentes-en-america-latina.pdf_

Ciriza, Alejandra (2015). Construir genealogías feministas desde el Sur: encrucijadas y tensiones. Millcayac, 2(3), 83104. https://revistas.uncu.edu.ar/ojs/index.php/millca-digital/article/view/523

Cole, Elizabeth. R (2008). Coalitions as a model for intersectionality: from practice to theory [Las coaliciones como modelo de interseccionalidad: de la práctica a la teoría]. Sex roles, 59(5-6), 443-453. doi: 10.1007/s11199-008-9419-1

Colectiva del Río Combahee (1988). Una declaración feminista negra. En C. Moraga y A. Castillo (Comp.) Esta puente, mi espalda. Voces de mujeres tercermundistas en los Estados Unidos (pp. 172-184). ISM.

Crenshaw, Kimberlée (1989). Demarginalizing the intersection of race and sex: a black feminist critique of antidiscrimination doctrine, feminist theory, and antiracist politics [Desmarginar la intersección de la raza y el sexo: una crítica feminista negra de la doctrina antidiscriminatoria, la teoría feminista y la política antirracista]. University of Chicago Legal Forum, 1989(8), 139-167. http://chicagounbound.uchicago.edu/uclf/vol1989/iss1/8

Crenshaw, Kimberlée (1991). Mapping the margins: intersectionality, identity politics, and violence against women of color [Mapeando los márgenes: interseccionalidad, políticas de identidad y violencia contra las mujeres de color]. Stanford Law Review, 43(6), 1241-1297. http://www.jstor.org/stable/1229039

Crenshaw, Kimberlée (2012). Cartografiando los márgenes. Interseccionalidad, políticas identitarias, y violencia contra las mujeres de color. En L. Platero (Ed.), Intersecciones: cuerpos y sexualidades en la encrucijada. Temas contemporáneos (pp. 87-122). Bellaterra.

10 Por meras formalizaciones entendemos a los procesos de neutralización crítica que sufren determinadas perspectivas, conceptos, términos e ideas cuando son adaptados a los parámetros de objetividad y cientificidad de las ciencias sociales. 
Curiel, Ochy (2010). Hacia la construcción de un feminismo descolonizado. En Y. Espinosa Miñoso (Coord.), Aproximaciones críticas a las prácticas teórico-políticas del feminismo latinoamericano (pp. 69-76). En la frontera.

Davis, Angela (1981). Women, race and class [Mujeres, raza y clase]. The women's press.

Davis, Angela (2003). Are prisons obsolete? [¿Son obsoletas las prisiones?]. Seven stories.

Davis, Angela (2012). I used to be your sweet mama. Ideología, sexualidad y domesticidad. En M. Jabardo (Ed.), Feminismos negros. Una Antología (pp. 135-185). Traficantes de sueños.

De Beauvoir, Simone (2019). El segundo Sexo. Debolsillo.

Espinosa Miñoso, Yuderkys (2019). Hacer genealogía de la experiencia: el método hacia una crítica a la colonialidad de la Razón feminista desde la experiencia histórica en América Latina. Revista direito e praxis, 10(3), 2007-2032. doi: http://dx.doi.org/10.1590/2179-8966/2019/43881

Federici, Silvia (2011). Calibán y la bruja. Mujeres, cuerpo y acumulación originaria. Colección nociones comunes. Tinta limón.

Gandarias Goikoetxea, Izar (2017). ¿Un neologismo a la moda?: Repensar la interseccionalidad como herramienta para la articulación política feminista. Investigaciones feministas, 8(1), 73-93. doi: https://doi.org/10.5209/infe.54498.

Gonzalez, Lélia (1983). Racismo e sexismo na cultura brasileira [Racismo y sexismo en la cultura brasileña]. En L. Machado da Silva (Ed.) Movimentos sociais urbanos, minorias étnicas e outros estudos (pp. 223-244). ANPOCS.

Gonzalez, Lélia (1988). A categoria político-cultural de amefricanidade [La categoría político-cultural de amefricanidad]. Tempo brasileiro, (92/93), 69-82.

González Ortuño, Gabriela (2016). Transmodernidad y feminismo en dos pensadoras caribeñas contemporáneas: Ochy Curiel y Yuderkys Espinosa. En J. G. Gandarilla (Comp.) La crítica en el margen. Hacia una cartografía conceptual para discutir la modernidad (pp. 521-536). Akal/Interpares.

González Ortuño, Gabriela (2018). Los feminismos afro en Latinoamérica y El Caribe, tradiciones disidentes: del pensamiento anticolonial a la defensa de la tierra. Investigaciones feministas, 9(2), 239-254. doi: https://doi. org/10.5209/INFE.58936

Gordon, Linda (2020). La interseccionalidad, el feminismo socialista y el activismo contemporáneo: reflexiones de una feminista socialista de la segunda ola. Zona franca. Revista de estudios de género, (28), 483-515. doi: https://doi. org/10.35305/zf.vi28.185

Grosfoguel, Ramón (2013). Racismo/sexismo epistémico, universidades occidentalizadas y los cuatro genocidios/ epistemicidios del largo siglo XVI. Tabula rasa, (16), 13-58.

Hill Collins, Patricia (1998). It's all in the family: intersections of gender, race and nation [Todo está en la familia: intersecciones de género, raza y nación]. Hypatia. Border crossings: Multicultural and posttcolonial feminist challenges to philosophy, 13(3), 62-82. doi: 10.1111/j.1527-2001.1998.tb01370.x

Hill Collins, Patricia (2000). Black feminist thought. Knowledge, consciousness, and the politics of empowerment [Pensamiento feminista negro. Conocimiento, conciencia y la política del empoderamiento]. Routledge.

Hill Collins, Patricia. (2012). Rasgos distintivos del pensamiento feminista negro. En M. Jabardo (Ed.) Feminismos negros. Una antología (pp. 99-134). Traficantes de sueños.

hooks, bell (1984). Choosing the margin as a space of radical openness [Elegir el margen como espacio de apertura radical]. En S. Harding (Comp.), The feminist standpoint theory reader (pp. 153-160). Routledge.

hooks, bell (2004). Mujeres negras. Dar forma a la teoría feminista. En b. hooks; A. Brah; C. Sandoval; G. Anzaldúa; A. Levins Morales; K. Bhavnani; M. Coulson; J. Alexander; C. Mohanty, Otras inapropiables. Feminismos desde las fronteras (pp. 33-50). Traficantes de sueños.

Krolokke, Charlotte y Scott Sorense, Anne (2006). Gender communication theories and analyses: from silence to performance [Teorías y análisis de la comunicación de género: del silencio a la performance]. Sage.

La Barbera, María Caterina (2016). Interseccionalidad, un 'concepto viajero’: orígenes, desarrollo e implementación en la Unión Europea. Interdisciplina, 4(8), 105-122. doi: http://dx.doi.org/10.22201/ceiich.24485705e.2016.8.54971

Lander, Eduardo (2016). Ciencias Sociales: saberes coloniales y eurocéntricos. En E. Lander (Comp.), La colonialidad del saber: eurocentrismo y ciencias sociales. Perspectivas latinoamericanas (pp. 15-44). Fundación CICCUS.

Lorde, Audre (1988). Las herramientas del amo nunca desarmarán la casa del amo. En Moraga, C. y Castillo, A. (Comp.) Esta puente mi espalda. Voces de mujeres tercermundistas de los Estados Unidos (pp. 89-93). ISM.

Lugones, María (2008). Colonialidad y género. Tabula rasa (9), 73-101.

Mattio, Eduardo (2012). ¿De qué hablamos cuando hablamos de género? Una introducción conceptual. En J. Morán Faúndes; J. Vaggione.; C. Sgró Ruata (Eds.), Sexualidades, desigualdades y derechos. Reflexiones en torno a los derechos sexuales y reproductivos (pp. 85-103). Ciencia, derecho y sociedad.

Medina Martín, Rocío (2014). Resignificaciones conceptuales y epistemológicas en el pensamiento político feminista eurocéntrico desde los feminismos periféricos. Cuadernos electrónicos de filosofía del derecho, (29), 72-98.

Mendoza, Breny (2014). Ensayos crítica feminista en Nuestramérica. Herder.

Neale, Jonathan (2003). La otra historia de la guerra de Vietnam. El Viejo Topo.

Ochoa, Karina (2012). Apuntes sobre la ausencia de la noción de 'sujeto político femenino' en el pensamiento ilustrado. Andamios. 9(20), 323-356. doi: http://dx.doi.org/10.29092/uacm.v9i20.383_ 
Parra, Fabiana (2018). La potencia de los feminismos latinoamericanos para una ruptura epistemológica con el universalismo eurocéntrico del feminismo hegemónico. Críticas desde el margen. Revista Latinoamericana del Colegio Internacional de Filosofia, 1(3), 85-101. http://sedici.unlp.edu.ar/handle/10915/97011

Parra, Fabiana (22-11-2019). La rebelión en Chile: la dignidad de Resistir. Diagonales.com. https://diagonales.com/app. php/contenido/la-rebelin-en-chile-la-dignidad-de-resistir/17782.

Parra, Fabiana (2021). Ideología y género: Subversión conceptual, lectura sintomal y genealogía política en Latinoamérica. Revista internacional de pensamiento político, 15, 409-430. https://doi.org/10.46661/revintpensampolit.5617

Pérez, Moira (2019). Violencia epistémica: reflexiones entre lo invisible y lo ignorable. El lugar sin límites, (1), 81-98.

Pérez, Moira y Bissutti, César (2021). Investigar en contextos de encierro. Notas sobre privilegio, lugar de enunciación y violencia estructural. Runa, (1), 227-245. doi: https://doi.org/10.34096/runa.v42i1.8510

Perlongher, Néstor (1997). Prosa plebeya. Colihue.

Platero, Lucas (2012). Introducción. La interseccionalidad como herramienta de estudio de la sexualidad. En L. Platero (Ed.), Intersecciones: cuerpos y sexualidades en la encrucijada. Temas contemporáneos (pp. 15-72). Bellaterra.

Radi, Blas (2020). ¿Qué es el tokenismo cisexista?. Revista anfibia. Universidad Nacional de San Martín. http:// revistaanfibia.com/ensayo/que-es-tokenismo-cisexista/

Sciortino, Silvana. (2014). Antropología y feminismos en América Latina: hacia una práctica descolonial. Teoría feminista y antropología: claves analíticas. Centro de estudios Ramón Areces.

Springer, Kimberly (2006). Chapter 4: black feminists respond to black power masculinism [Capítulo 4: las feministas negras responden al movimiento Black Power]. Peniel, J. (Ed.), The Black Power movement. Rethinking the Civil Rights - Black Power era (pp. 105-118). Taylor and Francis Group.

Stolcke, Verena (2004). La mujer es puro cuento: la cultura del género. Revista estudios feministas, 2(12), 77-105. doi: https://doi.org/10.1590/S0104-026X2004000200005.

TWWA (1971a). Triple jeopardy. Racism, imperialism, sexism [Triple opresión. Racismo, imperialismo, sexismo], 1(1).

TWWA (1971b). Triple jeopardy. Racism, imperialism, sexism [Triple opresión. Racismo, imperialismo, sexismo], 1(2).

Viveros Vigoya, Mara (2008). La sexualización de la raza y la racialización de la sexualidad en el contexto latinoamericano actual. En Careaga, G. Memorias del 1er. encuentro latinoamericano y del Caribe, La sexualidad frente a la sociedad (pp. 168-198). Universidad Nacional Autónoma de México.

Viveros Vigoya, Mara (2016). La interseccionalidad: una aproximación situada a la dominación. Debate feminista, (52). 1-17. Universidad Nacional Autónoma de México. doi: https://doi.org/10.1016/j.df.2016.09.005. 